Conclusions The experience of pain and pain management are between heaven and hell. However, a person-centered pain management are important independent on which pain relief given to achieve well managed pain.

\section{PROLONGED MOTOR BLOCK WITH PERSISTENT SAPHENOUS NEUROPATHY FOLLOWING COMBINED POPLITEAL/SAPHENOUS NERVE BLOCK FOR ANKLE SURGERY}

M Dobrić, B Vinceljek* , J Vukelić Slavić, T Beker. Clinical Hospital Center Sestre Milosrdnice, Traumatology Clinic, Zagreb, Croatia

\subsection{6/rapm-2021-ESRA.177}

Background and Aims Ultrasound guided peripheral nerve block for ankle surgery is appropriate alternative for spinal anaesthesia, allowing for earlier mobilization and adequate postoperative pain control.

Methods 38-year-old female, BMI 20.7, presented for hardware removal a year after an open reduction and internal fixation of bimalleolar ankle fracture. Ultrasound guided popliteal/saphenous nerve block was performed with spinal needle (G25, Quincke), using $0.5 \%$ levobupivacain and dexamethason as an adjuvant to local anaesthetic. Due to poor visualisation of saphenous nerve, paraesthesia was briefly elicited once during the procedure. Surgical procedure

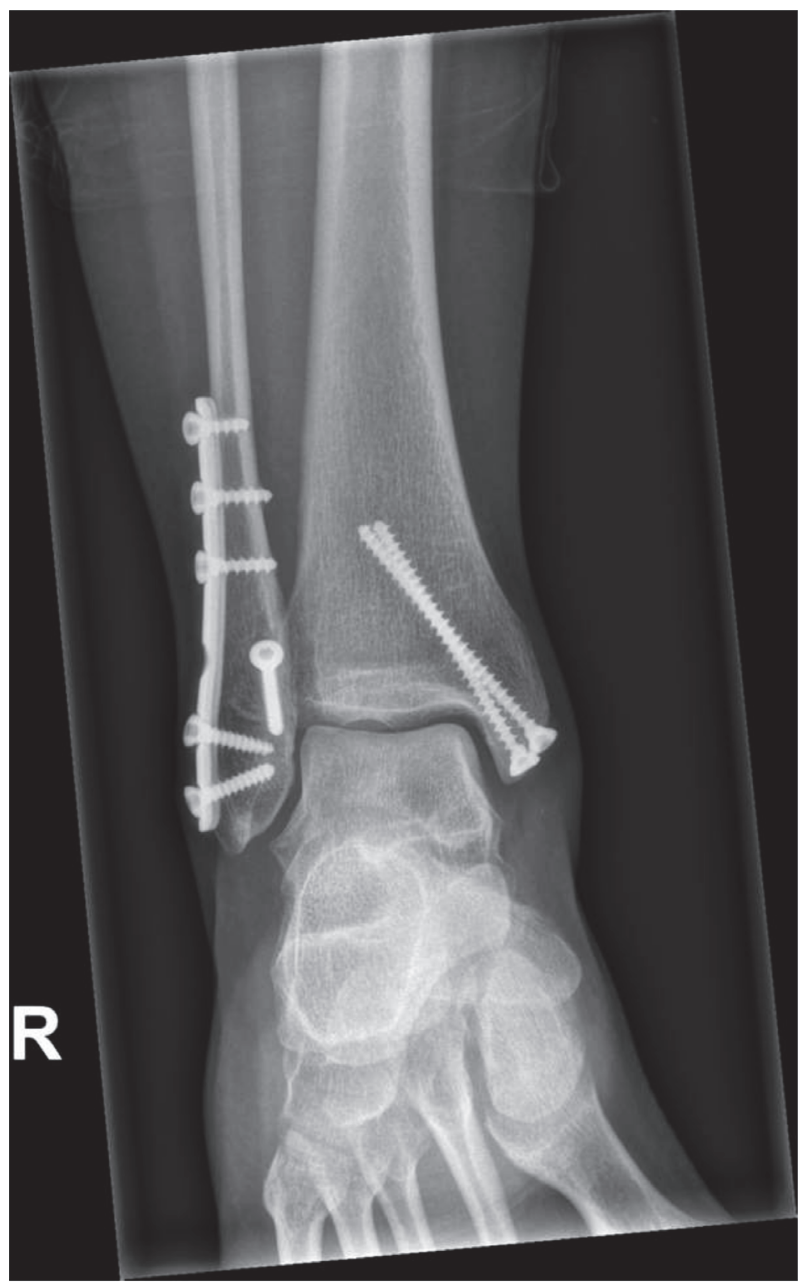

Abstract 177 Figure 1 went uneventfully, in complete surgical block and intravenous sedation with propofol. Motor block persisted for 48 hours, with full recovery thereafter. Sensory deficit in the distribution area of saphenous nerve was present one month after the procedure.

Results The patient was highly satisfied with postoperative pain control with no need for additional analgesics, but concerned about peristing tingling sensation. She declined proposed multimodal treatment for neuropathic pain with calcium channel antagonist pregabalin, and agreed to therapy with NSAID and vitamin B supplements. Further evaluation of eventual prolonged neuropathy, including NMR and nerve conduction studies, was discussed with patient.

Conclusions Dexamethasone prolongs the effect of local anaesthetic when used as an adjuvant. In our case, the duration of motor and sensory block was longer than expected. Complications related to peripheral nerve blocks may go undiagnosed until the first postoperative control. Neural lesions related to peripheral nerve blocks usually resolve within $4-7$ weeks and over $99 \%$ by one year.

\section{WALANT TECHNIQUE IMPROVES THE EFFICIENCY OF DISTAL NERVE BLOCKS FOR CARPAL TUNNEL RELEASE}

${ }^{1} \mathrm{M}$ Doirado*, ${ }^{2} \mathrm{~F}$ Le Sache, ${ }^{2} \mathrm{~L}$ Thomsen, ${ }^{3} \mathrm{G}$ Aziz, ${ }^{3} \mathrm{C}$ Naudin, ${ }^{3} \mathrm{M}$ Merzoug, ${ }^{2} \mathrm{D}$ Barouk,

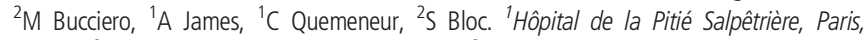
France; ${ }^{2}$ Clinique Drouot Sport, Paris, France; ${ }^{3}$ CMC Ambroise Paré, Neuilly Sur Seine, France

\subsection{6/rapm-2021-ESRA. 178}

Background and Aims Axillary block is the standard for carpal tunnel release (CTR), providing good anesthesia and tolerance of tourniquet. Distal blocks, efficient and preventing motor block, are less used due to a poor tolerance of tourniquet (1). This study was designed to assess the benefits of the addition of a tumescent local anesthesia (WALANT: Wide Awake Local Anesthesia No Tourniquet) to distal blocks during CTR.

Methods After approval of the Ethics Committee and written informed consent, 30 patients scheduled for CTR were enrolled in this prospective, randomized, open-label study.

Distal blocks (median - ulnar - lateral cutaneous nerve of forearm) were performed under ultrasound with Ropivacaine $0.375 \% \quad(5-7 \mathrm{ml})$ (TOURNIQUET and WALANT groups). In WALANT, an additional infiltration of $7 \mathrm{ml}$ lidocaine and epinephrine was performed in the area of

Abstract 178 Table 1 Patient characteristics

\begin{tabular}{|c|c|c|}
\hline & COETROL (n=15) & WaLART (hois) \\
\hline \multicolumn{3}{|l|}{ Demographica } \\
\hline Mavo, o (\$) & $8(53 \%)$ & $6(405)$ \\
\hline Femalo, $n(S)$ & $7(978)$ & $\theta(80 \mathrm{n})$ \\
\hline Aon, $y$ & $50.5=14.5$ & $55.6 \times 132$ \\
\hline BMS igghe & $28.4=4.5$ & $27.2 \pm 6$ \\
\hline \multicolumn{3}{|l|}{ Medical history } \\
\hline ASA seom & $2(1-3)$ & $2|1-2|$ \\
\hline Dubetes, o (s) & $2(135)$ & $10 \% 3$ \\
\hline Perphersi neuropesty, n (\$) & $0(0 \%)$ & $108 \%$ \\
\hline Altercopathy, n (is) & $3(200)$ & $\theta(7 \times)$ \\
\hline
\end{tabular}

